\title{
Bilateral Asymmetry of Upper Permanent Dentition in Six Archeological Pre-Conquest Samples from Colombia, South America
}

\author{
Carlos David Rodríguez-Flórez ${ }^{1 *}$ and Sonia E. Colantonio² \\ ${ }^{1}$ Grupo de Investigaciones ARQUEODIVERSIDAD, Museo Arqueológico “Julio César Cubillos," \\ Universidad del Valle - Colombia \\ ${ }^{2}$ Cátedra de Antropología Biológica y Cultural, Facultad de Ciencias Exactas, Físicas y Naturales, \\ Universidad Nacional de Córdoba - CONICET - Argentina
}

\begin{abstract}
Bilateral asymmetry is an important field of study in physical anthropology. The present study evaluated the frequencies of bilateral asymmetry of four traits (one for each tooth type in the maxillary arcade) in six pre-Conquest human archeological samples from
\end{abstract}

Bilateral symmetry is the antimeric repetition of the size and shape of a structure. In a morphological sense, symmetry can be defined as if the structure were divided into two or more parts exactly identical in size, shape, and position relative to the dividing point; in other words, the repetition is of exactly similar parts facing each other across the body's midline.

Van Valen (1962) grouped deviations from perfect symmetry in the structures of an organism into three types, namely (1) directional asymmetry (such as position of the mammalian heart); (2) antisymmetry (such as right- and left-handedness); and (3) fluctuating asymmetry (an asymmetry involving a paired structure that is usually distributed symmetrically). Fluctuating, mirror or flip symmetry may be either qualitative or quantitative. Bilateral asymmetry in tooth cusp occurrence (the presence or absence of a cusp on a tooth) is an example of qualitative fluctuating asymmetry (Staley and Green, 1971).

Theoretically, antimeric teeth should exhibit symmetrical mirror images of each other with respect both to size and surface detail (Scott, 1977). Some studies suggest that mirror imaging of asymmetry in twins likely results from chance effects of minor developmental disturbances between bilateral structures (Wetherell et al., 1994). Increased directional asymmetry has been reported in the occlusal morphology of first permanent molars from $45, \mathrm{X} / 46, \mathrm{XX}$ mosaics, indicating that the different cell lines (each regulated by different genes) may be responsible for the more pronounced differences
Colombia, South America. Results show the importance of a preliminary analysis of bilateral asymmetry in archeological fragmented samples and its relevance in molding subsequentinterpretations. Dental Anthropology 2007;20:19-23.

observed on left than right molars (Piriniemi et al., 1998).

Observations on the expressions of bilateral asymmetry in human dental morphological traits has been used in dental anthropology in a manner similar to a measure of population heritability (Garn et al., 1966a; Staley and Green, 1971; Baume and Crawford, 1979). Little metrical differences between antimeric teeth have been reported (Garn et al., 1966b; Garn and Bailey, 1977). Bailit et al. (1970) discuss their observations that metric fluctuating asymmetry values of tooth crown dimensions vary among human populations. In a study concerning the invariable bilateralism of Carabelli's trait (i.e., the suggestion that this trait always occurs bilaterally when present), Meredith and Hixon (1954) reported that, in fact, nearly $13 \%$ of their sample exhibited expression of the trait on just one side of the dental arch. Small side differences in trait expressions were reported by Wood and Green (1969) who compared the bilateralism of seven morphological traits in premolars of twins. Similar deductions for Carabelli's trait were reached by Scott (1972, cited in Scott, 1977) and by Biggerstaff (1973).

Another factor that can be important in evaluating

\footnotetext{
*Correspondence to: Carlos David Rodríguez-Flórez, Grupo de Investigaciones ARQUEODIVERSIDAD, Museo Arqueológico "Julio César Cubillos,"

Universidad del Valle - Colombia

E-mail: david@syllabapress.com
} 
the extent of bilateral asymmetry in a sample is sample size. Garn et al. (1979) showed how the effect of small samples (generally below 100 and in some cases as small as 15) increases the apparent intergroup differences in tooth crown asymmetry and, thus, how small sample sizes can influence biological interpretations.

\section{Dental asymmetry in fragmented archeological samples}

The use of morphological traits from the human dentition can create some problems of a methodological nature when studying fragmented archeological samples. One issue is the assumption of dental trait expression as individually immutable, in the sense of being morphologically symmetrical between homologous teeth.

In bioarcheology, estimating the frequency of a dental trait is influenced by the availability of samples and limited crown wear and the absence of caries (so the presence of the trait can be ascertained). Some authors recommend scoring the higher grade of expression for each dental trait (Turner and Scott, 1977) or counting both the left and right sides for each individual (Haeussler et al., 1988). In cases where the bioarcheologist only has fragmented remains (pieces from maxillas and mandibles) these counting methods are very practical. Either of these two recording methods maximizes the usable sample sizes without taking into account unilateral or bilateral trait expression. But, if we consider this affirmation in detail, an anthropological study on archeological samples could be carried out without a previous evaluation of bilateral asymmetry, thus underestimating possible environmental influences on trait expressions as much as over-estimating its taxonomic value and relevance in microevolutionary and historical inferences. At this point, researchers face a recording problem with only two possible alternatives: counting the trait as bilateral or discarding the individual, thus reducing the total sample size. There seem to be very few prior bioarcheological studies that deal with this issue of bilateral asymmetry as it relates to the development of biological distance calculations.

Taking into account that bilateral asymmetry could reflect environmental influences, and that bilateral trait asymmetries could affect a trait's usefulness in determining biological distances, we undertook a study of bilateral asymmetry on dental types.

Prior to using fragmented arches and traditional counting procedures for trait presence (Turner and Scott, 1977; Haeussler et al., 1988), bilateral analysis of available complete dental arches from the same sample can add elements that help develop useful comparative indicators in the crowns. The present study was carried out using six human pre-conquest samples from Colombia, with the aim of exploring the ranges of morphologic reliability of each dental type.

\section{MATERIALS AND METHODS}

This study consists of data from six pre-conquest human populations from Colombia dated between the VIII and XV centuries A.D. (Table 1). The sample sizes (n) correspond to the total number of individuals with complete arches that could be examined.

Permanent teeth of 58 individuals between 10 and 20 years of age with complete arches (maxilla) were selected (Fig. 1). The dental traits examined here are listed in Table 2. The ASU Dental Anthropology System was used to register the expression grade of incisor shovel shape, distal accessory ridge, and Carabelli's complex. The marginal ridges on the maxillary premolars were observed following the descriptions of Burnett (1996). A binary recording system was employed that consisted of grouping all trait expressions into either "present" (1) and "absent" (0) categories. Then, using these records, Molto's Bilateral Index (BI) was calculated with this formula:

$$
\mathrm{BI}=(\mathrm{bp} / \mathrm{bp}+\mathrm{up}) \times 100
$$

where BI is the Bilateral Index, bp is the count of cases (individuals) where the trait is present bilaterally, and up is the count of cases where the trait is present just unilaterally. The Bilateral Index quantifies the tendency for a trait to occur symmetrically. An index above 50 suggests a positive bilateral tendency for the trait (Tocheri, 2002). The standard deviation and coefficient of variation also were calculated for the assessments of intra- and inter-sample variation of bilateral traits' presence.

TABLE 1. Materials used in this study

\begin{tabular}{|c|c|c|c|c|}
\hline Sample & Centuries (A.D.) & Collection & Provenience & $\mathrm{n}$ \\
\hline Obando & VIII - XIII & Museo Arqueológico, Univalle & Valle del Cauca & 13 \\
\hline Guacanda & $X-X V$ & Museo Arqueológico, Univalle & Valle del Cauca & 9 \\
\hline La Escopeta & XIII - XV & Museo Arqueológico, Univalle & Valle del Cauca & 6 \\
\hline El Morro - Tambo & XIII - XV & Museo de Historia Natural, Unicauca & Cauca & 7 \\
\hline Marín & XIII - XV & Museo Nacional de Colombia & Cundinamarca & 11 \\
\hline Soacha & X - XIII & Museo Nacional de Colombia & Cundinamarca & 12 \\
\hline Total & & & & 58 \\
\hline
\end{tabular}




\section{RESULTS}

Bilateral and unilateral presence of traits and bilateral index values are shown in Table 3. Bilateral expressions of shovel shape (maxillary central incisor), distal accessory ridge (maxillary canine), and marginal ridges (maxillary first premolar) all show clear tendencies to occur bilaterally - with values higher 50 - and relatively low standard deviations (sd) and variation coefficients $(\mathrm{CV})$. In contrast, Carabelli's trait exhibits the highest sd and CV (Table 4). Comparing among the samples, exceptional values are found in La Escopeta, which has a CV higher than 50\% (Table 5).

\section{DISCUSSION}

With the assumed model of polygenetic inheritance, trait expression is due to interactions among a number of genes at different loci that interplay with environmental factors to produce the phenotypic expression of that trait. It is supposed that various genes have different contributions to phenotypic variation but they have an additive effect on the trait in question (Lauc et al., 2003). Dental asymmetry has generally been thought to be an indicator of developmental instability in humans and other animals. The occurrence of bilateral asymmetry can be interpreted as a reflection of instability in the normal development of a biological form (Palmer and Strobeck, 2003). Results of the present study suggest that the expression of Carabelli's complex (on UM1) is most easily influenced by environmental forces from among the several traits examined. BI values for Carabelli's trait were below 50 for Guacanda and for La Escopeta; both of these pre-conquest samples suggest that this trait would have low taxonomic value, at least in biological comparisons that involve these two samples. CV values for this trait $(37.3 \%)$ and his variation in the $\mathrm{La}$ Escopeta sample (50.1\%) support this conclusion. The comparatively high frequency of bilateral asymmetry for this dental trait could indicates its greater sensitivity to environmental stressors; comparably, these data may also imply changes in the gene pool of these prehistoric people. Other values greater but still close to a BI of 50 occurred in the samples from El Morro-Tambo (i.e., shovel shape UI1 BI = 66), Soacha (i.e., Carabelli UM1 $\mathrm{BI}=60$ ), and Guacanda (i.e., marginal ridges UP1 BI =

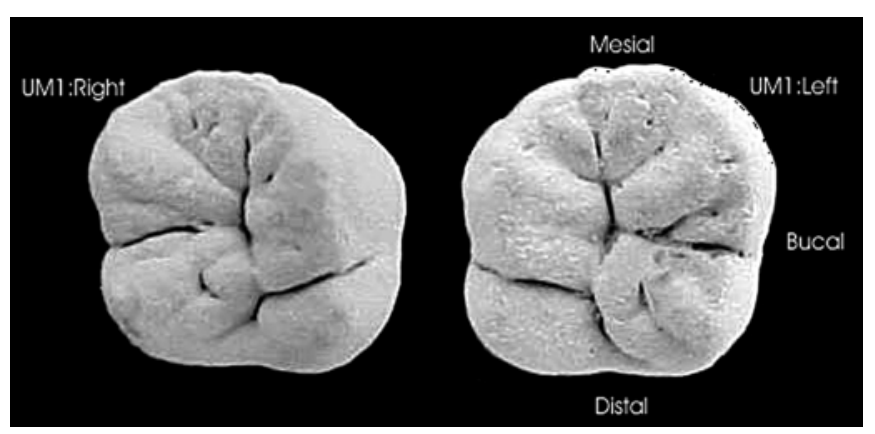

Fig. 1. UM1 of Indiviual 7 from La Escopeta.

57). The bilateral expression of these traits could also represent an environmental impact that could influence the phenetic component in the total sample. Of the traits studied, the distal accessory ridge displays the highest BI values, which promotes its reliability for use in phenetic inter-group comparisons.

An appreciation of the degree of bilateral expression of dental features such as Carabelli's trait, shovel shape incisors, and marginal ridges is valuable in order to assess the importance of previous bilateral asymmetry analysis in a prehistoric dental series. Estimating the bilateral index is useful for the observation of possible environmental influences that can affect the overall frequency of the trait expression sufficient to exclude Carabelli's trait in biological distances that polled all populations considered here.

Thanks to the present evaluation, analysis of the samples can be pursued more carefully in the validation of dental traits expressed for UM1 prior to phenetic analysis, in this case Carabelli's trait. To conclude, it is advisable to consider a bilateral analysis of fragmented archeological samples prior to the more complete investigation since it provides additional, insightful elements for among-sample interpretation.

\section{LITERATURE CITED}

Bailit HL, Workman PL, Niswander JD, McClean CJ. 1970. Dental asymmetry as an indicator of genetic and environmental conditions in human populations. Hum Biol 42:626-638.

TABLE 2. Dichotomization of trait expressions used in this study

\begin{tabular}{clccc}
\hline Tooth type & \multicolumn{1}{c}{ Trait } & Dichotomy & Presence & Absence \\
\hline UI1 & Shovel shape & 0 vs 16 & $1-6$ & 0 \\
UC & Distal Accesory Ridge & 0 vs 1-5 & $1-5$ & 0 \\
UP1 & Marginal Ridges & 0 vs 1 & 1 & 0 \\
UM1 & Carabelli's trait & 0 vs 1-6 & $1-6$ & 0 \\
\hline
\end{tabular}




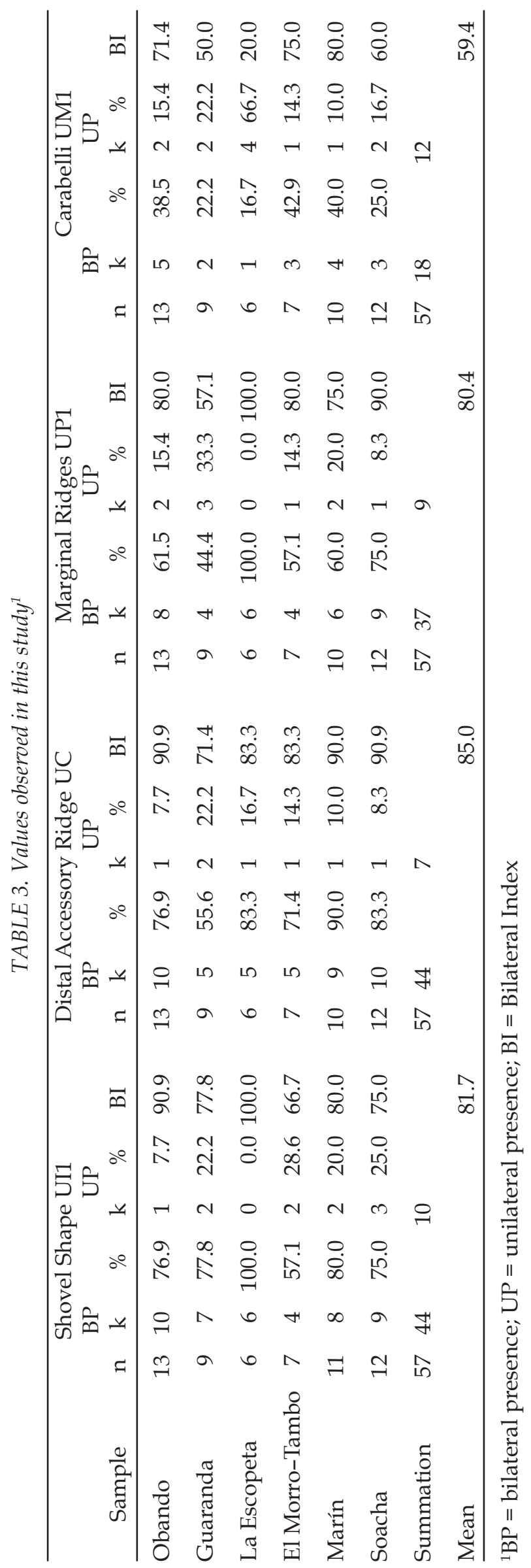


TABLE 4. BI statistics for each dental trait

\begin{tabular}{|c|c|c|c|c|}
\hline Sample & $\begin{array}{c}\text { Shovel shape } \\
\text { UI1 }\end{array}$ & $\begin{array}{c}\text { Distal Accesory Ridge } \\
\text { UC }\end{array}$ & $\begin{array}{c}\text { Marginal Ridges } \\
\text { UP1 }\end{array}$ & $\begin{array}{c}\text { Carabelli } \\
\text { UM1 }\end{array}$ \\
\hline Mean & 81.73 & 84.99 & 80.36 & 59.4 \\
\hline sd & 11.91 & 7.544 & 14.47 & 22.15 \\
\hline CV (\%) & 14.57 & 8.877 & 18.01 & 37.29 \\
\hline
\end{tabular}

${ }^{*} \mathrm{sd}=$ standard deviation. $\mathrm{CV}=$ coefficient of variation

TABLE 5. BI statistics calculated for each pre-conquest sample, all traits considered

\begin{tabular}{lcccccl}
\hline Statistic & Obando & Guaranda & La Escopeta & Morro-Tambo & Marín & Soacha \\
\hline Mean & 83.31 & 64.09 & 75.83 & 76.25 & 81.25 & 78.98 \\
sd & 9.445 & 12.75 & 38.04 & 7.249 & 6.292 & 14.6 \\
CV (\%) & 11.34 & 19.9 & 50.17 & 9.507 & 7.743 & 18.49 \\
\hline
\end{tabular}

Baume RM, Crawford MH. 1979. Discrete dental trait asymmetry in Mexico and Belize. J Dent Res 58:1811.

Biggerstaff RH. 1973. Heritability of the Carabelli cusp in twins. J Dent Res 52:40-44.

Burnett SE. 1996. A new look at premolar trait variation: maxillary premolar accessory ridges. Dental Anthropology 10:17-18.

Garn SM, Bailey SM. 1977. The symmetrical nature of bilateral asymmetry of deciduous and permanent teeth. J Dent Res 56:1422.

Garn SM, Cole PE, Smith BH. 1979. The effect of sample size on crown size asymmetry. J Dent Res 58:2012.

Garn SM, Lewis AB, Kerewsky RS. 1966a. Bilateral asymmetry and concordance in cusp number and crown morphology of the mandibular first molar. J Dent Res 45:1820.

Garn SM, Lewis AB, Kerewsky RS. 1966b. The meaning of bilateral asymmetry in the permanent dentition. J Dent Res 36:55-62.

Haeussler AM, Turner CG II, Irish JD. 1998. Concordance of American and Soviet methods in dental anthropology. Am J Phys Anthropol 75:218.

Lauc T, Rudan P, Rudan I. Campbell H. 2003. Effect of Inbreeding and endogamy on occlusal traits in human isolates. Am J Orthod 30:301-308.

Meredith HV, Hixon EH. 1954. Frequency. size. and bilateralism of Carabelli's tubercle. J Dent Res 33:435440.

Palmer AR, Strobeck C. 2003. Fluctuating asymmetry analyses revisited. In: Polak M, editor. Development instability: causes and consequences. Oxford: Oxford University Press, p. 279-319.
Piriniemi P, Alvesalo L, Silven O, Heikkila J, Julku J, Karjalahti P. 1998. Asymmetry in the occlusal morphology of first permanent molars in 45.X/46. XX mosaics. Arch Oral Biol 43:25-32.

Scott GR. 1977. Classification, sex dimorphism, association. and population variation of the canine distal accesory ridge. Hum Biol 49:453-469.

Staley RN, Green LJ. 1966. Bilateral asymmetry in tooth cusp occurrence in human monozygotic twins. dizygotic twins. and nontwins. J Dent Res 50:83-89.

Tocheri MW. 2002. The effects of sexual dimorphism, asymmetry, and inter-trait association on the distribution of thirteen deciduous dental nonmetric traits in a sample of Pima Amerindians. Dental Anthropology 15:1-8.

Wetherell J, Winning T, Townsend GC. 1994. Localized asymmetry in human dental crown form - an interesting case. Dental Anthropology 17:18-23.

Wood BF, Green LJ. 1969. Second premolar morphologic trait similarities in twins. J Dent Res 48:74-78.

Turner CG II, Scott GR. 1977. The dentition of Easter Islanders. In: Dahlberg AA, Graber TM, editors. Orofacial growth and development. The Hague: Mouton. p. 229-249.

Van Valen L. 1962. A study of fluctuating asymmetry. Evolution 16:125-142. 